\title{
Antioxidant Activities of Eremurus spectabilis M. Bieb. Extracts and Sulfur Compounds
}

\author{
Bertan Boran Bayrak' (D), Refiye Yanardag ${ }^{1}$ \\ IIstanbul University-Cerrahpasa, Faculty of Engineering, Department of Chemistry, Istanbul, Turkey
}

ORCID IDs of the authors: B.B.B. 0000-0002-0700-5096; R.Y. 0000-0003-4185-4363

Please cite this article as: Bayrak BB, Yanardag R. Antioxidant Activities of Eremurus spectabilis M. Bieb. Extracts and Sulfur Compounds. Eur J Biol 2021; 80(2): 154-163. DOI: 10.26650/EurJBiol.2021.1028656

\begin{abstract}
Objective: Eremurus spectabilis M. Bieb. is grown in East and Southeast Mediterranean regions of Turkey, and is commonly used as an edible plant in these regions. The aim of the current study was to determine the antioxidant activities of different E. spectabilis M. Bieb. extracts and some sulfur compounds.

Materials and Methods: In this study, the antioxidant activities of aqueous, ethanolic, and ethyl acetate extracts of $E$. spectabilis M. Bieb. and sulfur compounds (a-lipoic acid, cysteamine, cysteine, diallyl sulfide, glutathione, homocysteine, $\mathrm{N}$-acetyl cysteine, vitamin $\mathrm{U}$ and 1,4-dithioerythritol) were assessed in several antioxidant tests. These tests included reducing power, cupric ion reducing antioxidant capacity, 2,2'-azino-bis (3-ethylbenzothiazoline-6-sulfonic acid) radical scavenging, 2,2-diphenyl-1-picrylhydrazyl radical scavenging, N,N-dimethyl-4-phenylenediamine dihydrochloride radical scavenging, superoxide anion radical scavenging, hydroxyl radical scavenging, metal chelating activities and ferric ion reducing antioxidant power. The phytochemical profiles and total phenolic and flavonoid contents of all extracts were investigated.

Results: It was found out that the antioxidant activities of all the extracts and sulfur compounds generally increased with concentration increases, the highest antioxidant activity was found in ethyl acetate extract, while the aqueous extract was found to have the lowest antioxidant activity. Diallyl sulfide was found to have the highest antioxidant activity, whereas vitamin $U$ had the lowest antioxidant activity. It was observed that all extracts of E. spectabilis M. Bieb. and the sulfur compounds showed antioxidant activity.
\end{abstract}

Conclusion: The E. spectabilis M. Bieb. and sulfur compounds investigated in this study could be considered as a source of antioxidants.

Keywords: Eremurus spectabilis M. Bieb., antioxidant potential, sulfur compounds, free radicals, phytochemical screening

\section{INTRODUCTION}

Plants produce a variety of chemicals known as secondary metabolites. Many of these metabolites have been used by humans both nutritionally and for the treatment of illness or drug production. Most of the ancient civilizations in Anatolia produced many food and medicinal plants (1). Turkey is one of the richest countries in Europe and the Middle East in terms of natural flora. It has more than eleven thousand plant species due to its climate and geographical location. Approximately thirty-three percent of these plant species identified within the borders of Turkey are endemic (2).
The genus Eremurus (an important genus of Xanthorrhoeaceae that comprises 62 species) is widely known as foxtail lily or desert candles (3). It is found on dry and stony grazed hillside. This plant is naturally grown and geographically distributed in the regions of Central Asia, South Asia, East Asia, and the Middle East, including Turkey (4). Two Eremurus species, namely Eremurus spectabilis M. Bieb. and Eremurus cappadocicus, grow naturally and are localized in the Mediterranean, East and Southeast regions of Turkey (Eastern Anatolian part of Turkey). It is popularly referred to as "çiriş", "gulik", "gülük" and "sarı çiriş" in 
these regions (5). The plant has traditionally been consumed fresh and/or dried as a wild edible vegetable and as a traditional medicine/folk drug. Additionally, it has been shown in both ethnobotanical and ethnopharmacological studies that it is used for traditional treatment of gastrointestinal pain, liver diseases, diabetes, scabies and syphilis, rheumatism and various inflammations (6). In addition, a study by Abubaker and Hidayat showed that both water and hexane-ethanol extracts of $E$. spectabilis M. Bieb. exhibited antiproliferative effects against different cancer cell lines via its bioactive compounds (e.g., carvacrol, valence, cadelene) (7). These effects have been attributed to its richness in phenolics and flavonoids (8). In a recent study, it was shown that ethanolic and ethyl acetate extracts of $E$. spectabilis M. Bieb. have an inhibitive action against histone deacetylase, xanthine oxidase, and urease enzymes (9). In addition, the aqueous extract of this plant exhibits inhibitory effects on diabetes mellitus and skinassociated enzymes (i.e., a-amylase, a-glucosidase, elastase, hyaluronidase, and tyrosinase, respectively) (10).

Mopping up both reactive oxygen and nitrogen species (ROS and RNS) has been put forward as a crucial strategy in the suppression of the deleterious effects of oxidative stress, which give rise to the development of diseases, including cancer. Antioxidants are complex molecules, abundant in medicinal plants. They act as a protective shield for cells against the deleterious effects of ROS and RNS. In addition, antioxidants may easily neutralize free radicals (i.e., hydroxyl, peroxyl, and superoxide radicals) retarding them from binding with bioactive macromolecules (proteins, lipids, and DNA) in normal cells (11). The formation and elimination of free radicals are well-balanced, shifting of this balance to overproduction of free radicals causes oxidative stress, thus playing a crucial role in many diseases including tissue damage, inflammation, neurodegenerative diseases, cancer, and aging (8). It is also known that there are many antioxidant substances (especially synthetic ones) that fight against these negative effects of free radicals. On the other hand, it has been shown that the usage of synthetic antioxidants such as butylated hydroxyanisole and butylated hydroxytoluene cause potential health risks and toxicity as a result of their side effects (12). For this reason, there is currently an upsurge of interest in phytochemicals as a new source of both natural and novel antioxidants to be used in foods and pharmaceutical preparations to replace synthetic antioxidants (13).

Sulfur, one of the most essential chemical elements, is necessary for biochemical functions in all living organisms owing to its involvement in the structures of proteins, enzymes, amino acids (e.g., methionine and cysteine), and certain vitamins (e.g., thiamine and biotin) (14). In contrast to mammals (e.g., humans and monogastric animals), plants can utilise inorganic sulfur for synthesizing sulfur amino acids. Accordingly, plants are important sources of sulfur for most animals (15). These sulfur molecules can also be referred to as organosulfur compounds [for example, a-lipoic acid (ALA), cysteine (Cys), cystin, homocysteine (HCys), glutathione (GSH), taurine, vitamin $U$ (Vit U), and allylic sulfur compounds] which are found in cruciferous plants. In addition, they provide beneficial health effects by maintaining the redox balance through transmethylation/transsulfuration pathways in the cell (16).

All over the world, the number of side effects of treatment with herbal drugs is very low compared to synthetic drugs. They are also more accessible in terms of having a lower cost, thereby making these treatments/plants more attractive. Therefore, the usage and importance of herbal preparations that contain bioactive constituents such as organosulfur compounds in the treatment of various diseases is increasing. The aim of the current study was to determine the antioxidant activities of different $E$. spectabilis M. Bieb. extracts and sulfur compounds by using different methods.

\section{MATERIALS AND METHODS}

\section{Chemicals}

All chemicals used in the preparation of the extracts, and in the experiments were supplied by Sigma-Aldrich (St. Louis, MO, USA) or Merck (KGaA, Darmstadt, Germany). All other chemicals were of analytical grade.

\section{Herbal Material}

The fresh E. spectabilis M. Bieb. specimens (both roots and leaves) were obtained from local markets in the Eyup district of Istanbul/ Turkey. The plant was inspected and identified by Prof. Dr. Emine Akalin (Faculty of Pharmacy, Istanbul University). A specimen was deposited at the Faculty of Pharmacy Herbarium of Istanbul University (ISTE 93132). The plant samples were carefully washed three times with distilled water and then dried at room temperature. The dried plant was stored at $-20^{\circ} \mathrm{C}$ until required for use.

\section{Preparation of Extracts}

Dried and ground plant materials were used for extract preparation. The reflux system was used to for preparing an aqueous extract for $6 \mathrm{~h}$, which was then lyophilized. The amount of aqueous extract obtained was found to be $323.1 \% \mathrm{mg}$ dry weight (d.w.). Alongside this, both ethanolic and ethyl acetate extracts of the plant were prepared using the Soxhlet extractor for $6 \mathrm{~h}$. Thereafter, these extracts were evaporated under low pressure. The ethanolic and ethyl acetate extract amounts were found to be $436.6 \% \mathrm{mg}$ d.w. and $439.2 \% \mathrm{mg}$ d.w., respectively. All extracts were kept in a freezer at $-20^{\circ} \mathrm{C}$ before use.

\section{Phytochemical Analysis}

Phytochemical analysis of extracts was employed to investigate various major classes of secondary metabolites (e.g., alkaloids, anthraquinones, carbohydrates, diterpenes, flavonoids, phenolics, phytosterols, proteins, sulfurs, and tannins) using standard qualitative analysis methods (17).

\section{Assesment of Total Phenolic Contents (TPCs)}

To determine TPCs in all extracts of E. spectabilis M. Bieb., the method of Slinkard and Singleton was employed using Folin-Ciocalteau reagent (18). A reference solution of catechin (25-200 $\mu \mathrm{g} / \mathrm{mL}$ ) was employed to obtain the calibration curve. Thereafter, the TPCs in the E. spectabilis M. Bieb. extracts were calculated as $\mu \mathrm{g}$ of catechin equivalent per $\mathrm{mL}$ of extract. 


\section{Assesment of Total Flavonoid Contents (TFCs)}

TFCs in all extracts of E. spectabilis M. Bieb. were assessed employing the aluminum chloride colorometric method according to Zhishen et al., (19). A reference solution of pyrocatechin (25$300 \mu \mathrm{g} / \mathrm{mL}$ ) was used to obtain the calibration curve. Thereafter, the TFCs in the E. spectabilis M. Bieb. extracts were calculated as $\mu \mathrm{g}$ of pyrocatechin equivalent per $\mathrm{mL}$ of extract.

\section{Reducing Power Assay}

The reducing power of E. spectabilis $\mathrm{M}$. Bieb. extracts and sulfur compounds was determined using the method described by Oyaizu (20). As a reference solution, 6-hydroxy-2,5,7,8-tetramethylchromane-2-carboxylic acid (Trolox) was used. The intensity of the blue color is directly proportional to the reducing power of the tested samples. A high absorbance of the reaction mixture indicates a greater reducing power of the tested samples.

\section{Cupric lons $\left(\mathrm{Cu}^{2+}\right)$ Reducing Antioxidant Capacity (CUPRAC) Assay}

Total antioxidant capacities of E. spectabilis M. Bieb. extracts and sulfur compounds were obtained using $\mathrm{Cu}(\mathrm{II})$-neocuproine reagent according to Apak et al., (21). Trolox was used as a reference solution. The intensity of the yellow-orange color is directly proportional to the total antioxidant capacity of the tested samples. A high absorbance of the reaction mixture indicates a greater total antioxidant capacity of the tested samples.

\section{Ferric Reducing Antioxidant Power (FRAP) Assay}

The FRAP assay was carried out utilizing 2,4,6-tri(2-pyridyl)-Striazine $-\mathrm{FeCl}_{3}$ complex system according to Benzie and Strain (22). Reference solutions of $\mathrm{FeSO}_{4} \cdot 7 \mathrm{H}_{2} \mathrm{O}$ were employed to obtain the calibration curve. L-ascorbic acid and a-tocopherol were used as positive controls. The results were expressed as $\mu \mathrm{M} \mathrm{Fe}{ }^{2+}$ per $100 \mathrm{~mL}$ sample.

\section{ABTS Radical Scavenging Activity Assay}

ABTS [2,2'-azino-bis (3-ethylbenzothiazoline-6-sulfonic acid)] radical scavenging activities of the extracts of $E$. spectabilis $\mathrm{M}$. Bieb., sulfur compounds and reference antioxidant were completed using 2,2'-azino-bis (3-ethylbenzothiazoline-6-sulfonic acid) diammonium salt according to the discolorizing procedure of Arnao et al., (23). a-Tocopherol was used as a reference antioxidant. The ABTS radical scavenging activity was calculated using the following equation:

ABTS radical scavenging activity $(\%)=\left[\frac{\left(A_{0}-A_{1}\right)}{A_{0}}\right] \times 100$

$A_{0}$ is the absorbance of the initial concentration of ABTS

$A_{1}$ is the absorbance of the remaining concentration of ABTS in the presence of samples (or reference antioxidant).

\section{DPPH Radical Scavenging Activity Assay}

DPPH (2,2-diphenyl-1-picrylhydrazyl) radical scavenging activities of the extracts of $E$. spectabilis M. Bieb., sulfur compounds and reference antioxidant were estimated utilizing 2,2-diphenyl-1-picrylhydrazyl (DPPH) (24). Trolox was used as a reference antioxidant. The DPPH radical scavenging activity was calculated using the following equation:

DPPH radical scavenging activity $(\%)=\left[\frac{\left(A_{0}-A_{1}\right)}{A_{0}}\right] \times 100$

$\mathrm{A}_{0}$ is the absorbance of the initial concentration of DPPH

$A_{1}$ is the absorbance of the remaining concentration of DPPH in the presence of samples (or reference antioxidant).

\section{DMPD Radical Scavenging Activity Assay}

The determination of DMPD ( $\mathrm{N}, \mathrm{N}$-dimethyl-4-phenylenediamine) radical scavenging activity was performed using the $\mathrm{N}, \mathrm{N}$-dimethyl-4-phenylenediamine decolorization method developed by Fogliano et al., (25). Trolox was used as a reference antioxidant. The DMPD radical scavenging activity was calculated using the following equation:

DMPD radical scavenging activity $(\%)=\left[\frac{\left(A_{0}-A_{1}\right)}{A_{0}}\right] \times 100$

$A_{0}$ is the absorbance of the initial concentration of DMPD

$A_{1}$ is the absorbance of the remaining concentration of DMPD in the presence of samples (or reference antioxidant).

\section{Superoxide Radical Scavenging Activity Assay}

Superoxide radical scavenging activity of the extracts of $E$. spectabilis M. Bieb., sulfur compounds and reference antioxidant were employed according to Liu et al., (26) using the phenazine methosulfate -reduced nicotinamide adenine dinucleotide -nitroblue tetrazolium system. As a reference antioxidant, Trolox was used. The superoxide radical scavenging activity was calculated using the following equation:

The superoxide radical scavenging activity $(\%)=\left[\frac{\left(A_{0}-A_{1}\right)}{A_{0}}\right] \times 100(4)$ $A_{0}$ is the absorbance of control

$A_{1}$ is the absorbance of the sample (or reference antioxidant).

\section{Hydroxyl Radical Scavenging Activity Assay}

Hydroxyl radical scavenging activities of the extracts of $E$. spectabilis M. Bieb. and sulfur compounds were measured by the oxidation of 2-deoxy-D-ribose by the hydroxyl radical (27). Gallic acid (GA) was employed as a reference solution. The hydroxyl radical scavenging activity was calculated using the following equation:

Hydroxy radical scavenging activity $(\%)=\left[\frac{\left(A_{0}-A_{1}\right)}{A_{0}}\right] \times 100$

$A_{0}$ is the absorbance of the control

$A_{1}$ is the absorbance of the sample (or reference antioxidant).

\section{Metal Chelating Activity Assay}

The metal chelating activities of the extracts of $E$. spectabilis $M$. Bieb., sulfur compounds and reference antioxidants were determined using the 3-(2-pyridyl)-5,6-diphenyl-1,2,4-triazine-4',4"-disulfonic acid sodium salt (ferrozine)-Fe ${ }^{2+}$ complex method described by Decker and Welch (28). As reference antioxidants, a mixture containing ethylenediaminetetraacetic acid (EDTA) (or GA) was used instead of the sample. A low ab- 
sorbance indicates a higher chelating activity of the tested samples. The percentage inhibition of ferrozine- $\mathrm{Fe}^{2+}$ complex formation was calculated using the formula:

Metal chelating activity $(\%)=\left[\frac{\left(A_{0}-A_{1}\right)}{A_{0}}\right] \times 100$

$A_{0}$ is the absorbance of the control

$A_{1}$ is the absorbance of the samples (or reference antioxidants).

For all antioxidant activities, the extracts and sulfur compounds (or standards) concentration providing half maximum (50\%) inhibitions $\left(\mathrm{IC}_{50}\right)$ was calculated using regression equations (by plotting extract solution concentration versus percentage inhibition). A low $I C_{50}$ indicates a higher inhibitory potential of the tested plant extracts and sulfur compounds.

\section{RESULTS}

\section{Phytochemical Analysis}

The results of phytochemical analysis of all the extracts of $E$. spectabilis M. Bieb. are depicted in Table 1. The ethyl acetate extract of $E$. spectabilis M. Bieb. is rich in anthraquinones, diterpenes, flavonoids, phenolics, and proteins. On the other hand, anthraquinones and diterpenes were higher in the ethanolic extract, while the aqueous extract was only rich in phenolics. All other phytochemical constituents in the three extracts were detected in moderate or low quantities (Table 1).

\section{TPCs and TFCs of E. spectabilis M.Bieb.}

The TPCs and TFCs of all the extracts of E. spectabilis M. Bieb. are summarized in Table 2. It was found that the TPCs and TFCs of all extracts became elevated as the concentration increased. The highest TPCs and TFCs in all extracts was found at a concentration of $2500 \mu \mathrm{g} / \mathrm{mL}$ (Table 2). Meanwhile, in this concentration, the TPCs in all extracts of this plant (assessed using Folin-Ciocalteau reagent), were close to each other while the TFCs ranged from $34.64 \pm 0.55$ to $183.99 \pm 3.55 \mu \mathrm{g} / \mathrm{mL}$. The order for TPCs and TFCs of the extracts is as follows: ethanolic > ethyl acetate > aqueous extract and ethyl acetate $>$ ethanolic $>$ aqueous extract, respectively (Table 2 ).

Table 1. Phytochemical analysis of all extracts of Eremurus spectabilis M. Bieb.*

\begin{tabular}{lcccc}
\hline Phytochemicals & Aqueous Extract & Ethanolic Extract & Ethyl Acetate Extract & Methods \\
\hline Alkaloids & + & ++ & ++ & Hager's test \\
\hline Anthraquinones & + & +++ & +++ & Bornträger Test \\
\hline Carbohydrates & + & + & + & Molisch test \\
\hline Diterpenes & + & +++ & +++ & Cupric acetate test \\
\hline Flavonoids & + & ++ & +++ & Zhishen's test \\
\hline Phenolics & +++ & + & +++ & Millon's test \\
\hline Phytosterols & - & + & ++ & Lieberman Burchard's Test \\
\hline Proteins & + & ++ & +++ & Xanthoproteic test \\
\hline Sulfurs & + & + & ++ & Lead acetate test \\
\hline Tannins & + & ++ & ++ & Braemar's test
\end{tabular}

Table 2. Total phenolic contents and total flavonoid contents of all extracts of Eremurus spectabilis M. Bieb.

\begin{tabular}{lccc}
\hline Extracts & $\begin{array}{c}\text { Concentrations } \\
(\boldsymbol{\mu g} / \mathbf{m L})\end{array}$ & $\begin{array}{c}\text { TPCs } \\
(\boldsymbol{\mu g} \text { Catechin eq/mL)* }\end{array}$ & $\begin{array}{c}\text { TFCs } \\
(\boldsymbol{\mu g} \text { Pyrocatechin eq/mL)* }\end{array}$ \\
\hline Aqueous extract & 1500 & $46.53 \pm 0.79$ & $20.90 \pm 0.79$ \\
& 2000 & $52.80 \pm 0.26$ & $27.81 \pm 0.26$ \\
& 2500 & $62.80 \pm 0.55$ & $34.64 \pm 0.55$ \\
\hline Ethanolic extract & 1500 & $56.53 \pm 0.69$ & $42.09 \pm 0.69$ \\
& 2000 & $62.19 \pm 0.65$ & $61.38 \pm 0.65$ \\
\hline Ethyl acetate extract & 2500 & $80.37 \pm 2.27$ & $71.54 \pm 2.27$ \\
& 1500 & $52.60 \pm 0.18$ & $107.25 \pm 1.78$ \\
\end{tabular}

*Mean \pm standard deviation ( $n=3$ ), TPCs: Total phenolic contents, TFCs: Total flavonoid contents. 


\section{Reducing Power, CUPRAC Levels, and FRAP Values of $E$. spectabilis M.Bieb. Extracts and Sulfur Compounds}

The reducing power, CUPRAC levels, and FRAP values of all the extracts of $E$. spectabilis M. Bieb., sulfur compounds and reference antioxidants are presented in Table 3. In the current study, it was found that reducing power, CUPRAC levels, and FRAP values of all tested samples elevated with an increase in concentration (Table 3). At $1000 \mu \mathrm{g} / \mathrm{mL}$ for all extracts and Trolox, it was observed that reducing power and CUPRAC levels decreased as follows, respectively: Trolox (1.705 \pm 0.009 and $2.705 \pm 0.144)>$ ethyl acetate $(0.822 \pm 0.002$ and $0.225 \pm 0.006)$ $>$ ethanolic $(0.684 \pm 0.002$ and $0.185 \pm 0.004)>$ aqueous extract $(0.318 \pm 0.011$ and $0.050 \pm 0.002)$ (Table 3$)$. When the sulfur compounds were compared, it was seen that their reducing power and CUPRAC values diminished in the order of: Diallyl sulfide (DAS) > HCys > N-Acetylcysteine (NAC) > GSH > Cys > ALA > Vit $\mathrm{U}$ and $\mathrm{CysNH}_{2}>\mathrm{Cys}>\mathrm{HCys}>1,4-\mathrm{DTE}>\mathrm{NAC}>\mathrm{GSH}>\mathrm{DAS}>$ ALA > Vit U, respectively (Table 3). At $250 \mu \mathrm{g} / \mathrm{mL}$ concentration, FRAP values of aqueous, ethanolic, and ethyl acetate extracts were found to be very close $\left(15.92 \pm 0.76 \mu \mathrm{M} \mathrm{Fe}^{2+}, 13.33 \pm 0.90 \mu \mathrm{M}\right.$ $\mathrm{Fe}^{2+}$, and $17.94 \pm 0.49 \mu \mathrm{M} \mathrm{Fe}^{2+}$, respectively), they exhibited weak FRAP values as compared to standard $\left(350.21 \pm 1.12 \mu \mathrm{M} \mathrm{Fe}^{2+}\right.$ for L-ascorbic acid). Of the sulfur compounds, ALA had a much better FRAP value than the standard compound (Table 3).

\section{ABTS, DPPH and DMPD Radical Scavenging Activities of $E$. spectabilis M.Bieb. Extracts and Sulfur Compounds}

The ABTS, DPPH and DMPD radical scavenging activities of $E$. spectabilis M. Bieb. extracts and sulfur compounds are shown in Table 4. The results depict half-maximal inhibition concentrations $\left(\mathrm{IC}_{50}\right)$ values of the ABTS, DPPH and DMPD radical scavenging activities of the samples. The $I C_{50}$ values were calculated by plotting the inhibition percentage values as a function of their concentrations. $\mathrm{IC}_{50}$ is defined as the concentration of a sample that gives rise to $50 \%$ of free radicals neutralization. Thus, the lower the $I C_{50}$ value, the higher the radical scavenging activity. In our study, the $\mathrm{IC}_{50}$ values ranging from $312.71 \pm 6.74$ to $469.43 \pm 13.24 \mu \mathrm{g} / \mathrm{mL}$ for ABTS, $0.409 \pm 0.004$ to $0.843 \pm 0.019 \mathrm{mg} /$ $\mathrm{mL}$ for $\mathrm{DPPH}$, and $75.43 \times 10^{-9} \pm 1.61 \times 10^{-9} \mathrm{mg} / \mathrm{mL}$ to $0.100 \pm 0.0006$ $\mathrm{mg} / \mathrm{mL}$ for DMPD were recorded for aqueous, ethanolic and eth$\mathrm{yl}$ acetate extracts, while the $\mathrm{IC}_{50}$ values of $102.45 \pm 1.90 \mu \mathrm{g} / \mathrm{mL}$ and $0.012 \pm 0.0002 \mathrm{mg} / \mathrm{mL}$ and $0.001 \pm 0.0001 \mathrm{mg} / \mathrm{mL}$ were found for a-tocopherol and Trolox, respectively (Table 4). Considering the high antioxidant activities (associated with the lower $\mathrm{IC}_{50}$ values), it was found that the $I C_{50}$ values of all extracts had been higher ABTS and DPPH radical scavenging activities than standards (a-tocopherol and Trolox, respectively). In contrast, both ethanolic and ethyl acetate extracts were found to be stronger DMPD radical scavengers than aqueous extract and Trolox (Table 4). Comparisons show that the sulfur compounds (excluding Vit U and DAS) exhibited greater ABTS radical scavenging activities than a-tocopherol, while only $\mathrm{CysNH}_{2}$ exhibited better DPPH radical scavenging activity than Trolox. On the other hand, of the sulfur compounds, it was seen that DAS had the best DMPD scavenging activity. In addition to our DMPD results, GSH, NAC, and 1,4-DTE had the same $I C_{50}$ values as Trolox (Table 4).
Superoxide Radical, Hydroxyl Radical Scavenging, and Metal Chelating Activities of E. spectabilis M.Bieb. Extracts and Sulfur Compounds

Superoxide radical, hydroxyl radical scavenging, and metal chelating activities of all the extracts of E. spectabilis M. Bieb. and sulfur compounds are summarized in Table 5 . In the current study, the $I C_{50}$ values of superoxide radical scavenging activities of extracts were found to be as follows: aqueous $(17.62 \pm 0.65 \mu \mathrm{g} /$ $\mathrm{mL})$, ethanolic $(21.77 \pm 0.64 \mu \mathrm{g} / \mathrm{mL})$, and ethyl acetate $(8.83 \pm 1.64$ $\mu \mathrm{g} / \mathrm{mL}$ ) extracts. As seen in Table 5, all extracts were stronger superoxide radical scavengers than Trolox (Table 5). Of the sulfur compounds, both DAS and HCys exhibited almost the same strong $\mathrm{IC}_{50}$ values as superoxide radicals $(0.026 \pm 0.0003 \mu \mathrm{g} / \mathrm{mL}$ for DAS and $0.027 \pm 0.0004 \mu \mathrm{g} / \mathrm{mL}$ for HCys) (Table 5). The superoxide radical scavenging activities decreased in the order of: DAS $>$ HCys $>\mathrm{NAC}>\mathrm{GSH}>1,4-\mathrm{DTE}>\mathrm{CysNH}_{2}>\mathrm{Cys}>\mathrm{Vit} \mathrm{U}>\mathrm{ALA}$ (Table 5). Herein, the hydroxyl radicals scavenging activities of extracts decreased in the order of: ethanolic $\left(7.82 \times 10^{-3} \pm 0.09 \times 10^{-3}\right.$ $\mathrm{mg} / \mathrm{mL})>$ ethyl acetate $\left(8.93 \times 10^{-3} \pm 0.33 \times 10^{-3} \mathrm{mg} / \mathrm{mL}\right)>$ aqueous $(44.41 \pm 0.03 \mathrm{mg} / \mathrm{mL})$ extracts. Comparisons show that the hydroxyl radical scavenging activities for the sulfur compounds (excluding ALA and DAS) were higher than that of the standard (GA), whereas Vit $U$ had low hydroxyl radical scavenging activity (Table 5). As for metal chelating activities, all extracts had a greater tendency to metal chelation as compared to GA. The metal chelating activities of sulfur compounds decreased as follows: EDTA $>\mathrm{CysNH}_{2}>$ DAS $>1,4-\mathrm{DTE}>\mathrm{Cys}>\mathrm{ALA}>\mathrm{Vit} \mathrm{U}>\mathrm{NAC}$ $>$ HCys $>$ GSH (Table 5).

\section{DISCUSSION}

The value of medicinal herbs is associated with having the major biologically active constituents known as secondary metabolites. This makes them an important natural source for usage in either traditional or conventional medicine. However, their values can be specified by the diversity of their phytochemical constituents which produce a certain physiological effect on the organism (29). These phytochemicals may be distinguished in several ways, which are based on their biosynthetic origin, solubility properties, and the presence of key chemical groups (30). In a recent study, Güler et al., reported that wild medicinal plants were more preferred than cultivated species (2).

Wild edible and medicinal plants like E. spectabilis M. Bieb., which contain natural ingredients rich in bioactive compounds (such as phenolics and flavonoids), have attracted attention due to their biological properties. They exhibit antioxidant activity and are considered as a good alternative to synthetic antioxidants (12). From this point of view, this work was designed to investigate the antioxidant activities of the aqueous, ethanolic and ethyl acetate extracts of E. spectabilis M. Bieb. and certain sulfur compounds.

Phytochemicals are the essence of plant-based drugs; the efficacy of their therapeutic role is directly proportional to the richness of these constituents in plants (31). In this study, the phytochemical consituents (e.g., alkaloids, flavonoids, phenolics etc.) 
Table 3. Reducing power, total antioxidant capacity levels, and ferric reducing antioxidant power values of all extracts of Eremurus spectabilis M. Bieb. and sulfur compounds.

\begin{tabular}{|c|c|c|c|c|c|c|}
\hline $\begin{array}{l}\text { Extracts } \\
\text { /Sulfur Comp. } \\
\text { /Standards }\end{array}$ & $\begin{array}{l}\text { Conc. } \\
(\mu \mathrm{g} / \mathrm{mL})\end{array}$ & $\begin{array}{l}\text { Reducing } \\
\text { Power*," }\end{array}$ & $\begin{array}{c}\text { Conc. } \\
(\mu \mathrm{g} / \mathrm{mL})\end{array}$ & CUPRAC*,\# & $\begin{array}{l}\text { Conc. } \\
(\mu \mathrm{g} / \mathrm{mL})\end{array}$ & $\begin{array}{c}\text { FRAP } \\
\left(\mu \mathrm{M} \mathrm{Fe}^{2+}\right)^{*}\end{array}$ \\
\hline \multirow[t]{3}{*}{ Aqueous extract } & 600 & $0.248 \pm 0.001$ & 600 & $0.023 \pm 0.005$ & 250 & $15.92 \pm 0.76$ \\
\hline & 800 & $0.292 \pm 0.001$ & 800 & $0.034 \pm 0.003$ & 500 & $23.89 \pm 0.43$ \\
\hline & 1000 & $0.318 \pm 0.011$ & 1000 & $0.050 \pm 0.002$ & 1000 & $44.09 \pm 1.49$ \\
\hline \multirow[t]{3}{*}{ Ethanolic extract } & 600 & $0.485 \pm 0.007$ & 600 & $0.122 \pm 0.003$ & 250 & $13.33 \pm 0.90$ \\
\hline & 800 & $0.592 \pm 0.008$ & 800 & $0.154 \pm 0.003$ & 500 & $18.95 \pm 0.79$ \\
\hline & 1000 & $0.684 \pm 0.002$ & 1000 & $0.185 \pm 0.004$ & 1000 & $31.99 \pm 0.52$ \\
\hline \multirow[t]{3}{*}{ Ethyl acetate extract } & 600 & $0.619 \pm 0.005$ & 600 & $0.147 \pm 0.002$ & 250 & $17.94 \pm 0.49$ \\
\hline & 800 & $0.735 \pm 0.001$ & 800 & $0.181 \pm 0.006$ & 500 & $28.96 \pm 0.76$ \\
\hline & 1000 & $0.822 \pm 0.002$ & 1000 & $0.225 \pm 0.006$ & 1000 & $50.43 \pm 1.05$ \\
\hline \multirow[t]{3}{*}{ ALA } & 600 & $0.104 \pm 0.002$ & 500 & $0.012 \pm 0.001$ & 2.5 & $35.73 \pm 0.58$ \\
\hline & 800 & $0.114 \pm 0.002$ & 750 & $0.025 \pm 0.002$ & 5 & $65.60 \pm 0.88$ \\
\hline & 1000 & $0.132 \pm 0.003$ & 1000 & $0.031 \pm 0.003$ & 10 & $127.65 \pm 0.58$ \\
\hline \multirow[t]{3}{*}{ Cys } & 60 & $0.229 \pm 0.002$ & 50 & $0.406 \pm 0.002$ & 25 & $9.23 \pm 0.29$ \\
\hline & 80 & $0.274 \pm 0.001$ & 75 & $0.564 \pm 0.006$ & 50 & $12.01 \pm 0.32$ \\
\hline & 100 & $0.331 \pm 0.003$ & 100 & $0.688 \pm 0.003$ & 100 & $18.73 \pm 0.58$ \\
\hline \multirow[t]{3}{*}{$\mathrm{CysNH}_{2}$} & 60 & $0.131 \pm 0.001$ & 50 & $0.460 \pm 0.004$ & 250 & $9.22 \pm 0.29$ \\
\hline & 80 & $0.171 \pm 0.002$ & 75 & $0.556 \pm 0.006$ & 500 & $11.33 \pm 0.44$ \\
\hline & 100 & $0.188 \pm 0.004$ & 100 & $0.731 \pm 0.004$ & 1000 & $18.73 \pm 0.58$ \\
\hline \multirow[t]{3}{*}{ DAS } & 0.001 & $0.081 \pm 0.004$ & 50 & $0.006 \pm 0.002$ & 250 & $12.77 \pm 0.17$ \\
\hline & 0.01 & $0.091 \pm 0.001$ & 75 & $0.009 \pm 0.001$ & 500 & $14.31 \pm 0.44$ \\
\hline & 0.1 & $0.099 \pm 0.002$ & 100 & $0.014 \pm 0.001$ & 1000 & $17.00 \pm 0.58$ \\
\hline \multirow[t]{3}{*}{ GSH } & 60 & $0.245 \pm 0.003$ & 50 & $0.140 \pm 0.003$ & 250 & $23.34 \pm 1.15$ \\
\hline & 80 & $0.294 \pm 0.002$ & 75 & $0.216 \pm 0.005$ & 500 & $41.40 \pm 1.16$ \\
\hline & 100 & $0.355 \pm 0.004$ & 100 & $0.302 \pm 0.003$ & 1000 & $77.03 \pm 1.01$ \\
\hline \multirow[t]{3}{*}{ HCys } & 60 & $0.522 \pm 0.005$ & 50 & $0.303 \pm 0.004$ & 250 & $34.67 \pm 1.76$ \\
\hline & 80 & $0.641 \pm 0.002$ & 75 & $0.430 \pm 0.006$ & 500 & $64.45 \pm 1.92$ \\
\hline & 100 & $0.736 \pm 0.004$ & 100 & $0.600 \pm 0.004$ & 1000 & $122.66 \pm 2.04$ \\
\hline \multirow[t]{3}{*}{ NAC } & 60 & $0.326 \pm 0.001$ & 50 & $0.290 \pm 0.007$ & 25 & $31.22 \pm 0.72$ \\
\hline & 80 & $0.404 \pm 0.002$ & 75 & $0.360 \pm 0.004$ & 50 & $60.03 \pm 0.72$ \\
\hline & 100 & $0.433 \pm 0.003$ & 100 & $0.502 \pm 0.005$ & 100 & $114.28 \pm 1.45$ \\
\hline \multirow[t]{3}{*}{ Vit U } & 600 & $0.094 \pm 0.002$ & 5000 & $0.024 \pm 0.002$ & 2.5 & $6.79 \pm 0.03$ \\
\hline & 800 & $0.101 \pm 0.002$ & 7500 & $0.035 \pm 0.003$ & 5 & $7.00 \pm 0.03$ \\
\hline & 1000 & $0.108 \pm 0.001$ & 10000 & $0.042 \pm 0.001$ & 10 & $7.38 \pm 0.05$ \\
\hline \multirow[t]{3}{*}{ 1,4-DTE } & 60 & $0.456 \pm 0.001$ & 50 & $0.348 \pm 0.003$ & 25 & $61.38 \pm 0.86$ \\
\hline & 80 & $0.558 \pm 0.001$ & 75 & $0.474 \pm 0.006$ & 50 & $122.47 \pm 1.75$ \\
\hline & 100 & $0.704 \pm 0.004$ & 100 & $0.585 \pm 0.004$ & 100 & $225.63 \pm 1.44$ \\
\hline \multirow[t]{3}{*}{ Trolox ${ }^{a}$} & 600 & $1.602 \pm 0.003$ & 600 & $2.568 \pm 0.046$ & - & - \\
\hline & 800 & $1.661 \pm 0.010$ & 800 & $2.636 \pm 0.041$ & & \\
\hline & 1000 & $1.705 \pm 0.009$ & 1000 & $2.705 \pm 0.144$ & & \\
\hline \multirow[t]{3}{*}{ a-Tocopherol ${ }^{b}$} & - & - & - & - & 50 & $31.12 \pm 1.24$ \\
\hline & & & & & 100 & $56.38 \pm 1.66$ \\
\hline & & & & & 250 & $146.77 \pm 1.59$ \\
\hline \multirow[t]{3}{*}{ L-Ascorbic acid } & - & - & - & - & 50 & $93.94 \pm 0.91$ \\
\hline & & & & & 100 & $186.54 \pm 1.23$ \\
\hline & & & & & 250 & $350.21 \pm 1.12$ \\
\hline
\end{tabular}


Table 4. 2,2'-Azino-bis(3-ethylbenzothiazoline-6-sulfonic acid), 2,2-Diphenyl-1-picrylhydrazyl, N,N-dimethyl-4phenylenediamine radical scavenging activities of all extracts of Eremurus spectabilis M. Bieb. and sulfur compounds.

\begin{tabular}{|c|c|c|c|}
\hline $\begin{array}{l}\text { Extracts } \\
\text { /Sulfur Compounds } \\
\text { /Standards }\end{array}$ & $\begin{array}{c}\text { ABTS } \\
I_{50}(\mu \mathrm{g} / \mathrm{mL})^{*}\end{array}$ & $\begin{array}{c}\text { DPPH } \\
I^{I} C_{50}(\mathrm{mg} / \mathrm{mL}) *\end{array}$ & $\begin{array}{c}\text { DMPD } \\
I C_{50}(\mathrm{mg} / \mathrm{mL})^{*}\end{array}$ \\
\hline Aqueous extract & $469.43 \pm 13.24$ & $0.409 \pm 0.004$ & $0.100 \pm 0.0006$ \\
\hline Ethanolic extract & $312.71 \pm 19.94$ & $0.482 \pm 0.003$ & $75.43 \times 10^{-9} \pm 1.61 \times 10^{-9}$ \\
\hline Ethyl acetate extract & $375.01 \pm 6.74$ & $0.843 \pm 0.019$ & $80.20 \times 10^{-9} \pm 1.31 \times 10^{-9}$ \\
\hline ALA & $98.18 \pm 0.15$ & $126.33 \pm 12.83$ & $0.88 \pm 0.01$ \\
\hline Cys & $31.74 \pm 0.53$ & $0.015 \pm 0.0002$ & $0.005 \pm 0.0001$ \\
\hline $\mathrm{CysNH}_{2}$ & $9.12 \pm 0.06$ & $0.009 \pm .0002$ & $0.004 \pm 0.0001$ \\
\hline DAS & $290.92 \pm 31.94$ & $0.198 \pm 0.016$ & $7.96 \times 10^{-9} \pm 0.82 \times 10^{-9}$ \\
\hline GSH & $58.65 \pm 0.92$ & $0.081 \pm 0.003$ & $0.001 \pm 0.0002$ \\
\hline HCys & $25.66 \pm 0.21$ & $0.041 \pm 0.002$ & $0.005 \pm 0.0002$ \\
\hline NAC & $13.96 \pm 0.68$ & $0.025 \pm 0.0002$ & $0.001 \pm 0.0001$ \\
\hline Vit U & $153.11 \pm 4.12$ & $0.232 \pm 0.0002$ & $50.04 \pm 1.48$ \\
\hline 1,4-DTE & $35.30 \pm 1.13$ & $0.029 \pm 0.0002$ & $0.001 \pm 0.0001$ \\
\hline a-Tocopherol ${ }^{a}$ & $102.45 \pm 1.90$ & - & - \\
\hline Trolox $^{b, c}$ & - & $0.012 \pm 0.0002$ & $0.001 \pm 0.0001$ \\
\hline
\end{tabular}

Table 5. Superoxide radical, hydroxyl radical scavenging, and metal chelating activities of all extracts of Eremurus spectabilis M. Bieb. and sulfur compounds.

\begin{tabular}{|c|c|c|c|}
\hline $\begin{array}{l}\text { Extracts } \\
\text { /Sulfur Compounds } \\
\text { /Standards }\end{array}$ & $\begin{array}{l}\text { Superoxide Radical } \\
\text { Scavenging Activities } \\
\qquad \mathrm{IC}_{50}(\mu \mathrm{g} / \mathrm{mL})^{*}\end{array}$ & $\begin{array}{l}\text { Hydroxyl Radical Scavenging } \\
\text { Activities } \\
\qquad \mathrm{IC}_{50}(\mathrm{mg} / \mathrm{mL}) *\end{array}$ & $\begin{array}{l}\text { Metal Chelating Activities } \\
\qquad \mathrm{IC}_{50}(\mathrm{mg} / \mathrm{mL})^{*}\end{array}$ \\
\hline Aqueous extract & $17.62 \pm 0.65$ & $44.41 \pm 0.03$ & $0.74 \pm 0.01$ \\
\hline Ethanolic extract & $21.77 \pm 0.64$ & $7.82 \times 10^{-3} \pm 0.09 \times 10^{-3}$ & $0.82 \pm 0.03$ \\
\hline Ethyl acetate extract & $8.83 \pm 1.64$ & $8.93 \times 10^{-3} \pm 0.33 \times 10^{-3}$ & $1.01 \pm 0.01$ \\
\hline ALA & $157.25 \pm 4.71$ & $7.99 \times 10^{-9} \pm 1.25 \times 10^{-9}$ & $23.38 \pm 0.79$ \\
\hline Cys & $37.10 \pm 2.32$ & $50.05 \pm 1.26$ & $8.71 \pm 0.09$ \\
\hline CysNH ${ }_{2}$ & $20.09 \pm 1.57$ & $48.14 \pm 0.99$ & $0.038 \pm 0.002$ \\
\hline DAS & $0.026 \pm 0.0003$ & $8.39 \times 10^{-9} \pm 0.05 \times 10^{-9}$ & $0.38 \pm 0.04$ \\
\hline GSH & $5.11 \pm 0.28$ & $36.42 \pm 0.76$ & $110.37 \pm 5.38$ \\
\hline HCys & $0.027 \pm 0.0004$ & $0.55 \pm 0.02$ & $55.61 \pm 6.51$ \\
\hline NAC & $0.78 \pm 0.01$ & $29.07 \pm 1.04$ & $46.65 \pm 2.47$ \\
\hline Vit U & $52.16 \pm 1.73$ & $92.00 \pm 2.16$ & $39.50 \pm 0.06$ \\
\hline 1,4-DTE & $19.81 \pm 0.91$ & $42.16 \pm 1.08$ & $0.47 \pm 0.01$ \\
\hline Trolox ${ }^{a}$ & $25.34 \pm 1.07$ & - & - \\
\hline a-Tocopherolb & - & $9.24 \times 10^{-3} \pm 0.14 \times 10^{-3}$ & - \\
\hline $\mathbf{G A}^{\mathrm{b}, \mathrm{c}}$ & - & $77.13 \pm 5.56$ & $35.57 \pm 0.87$ \\
\hline EDTA $^{c}$ & - & - & $0.034 \pm 0.003$ \\
\hline \multicolumn{4}{|c|}{ 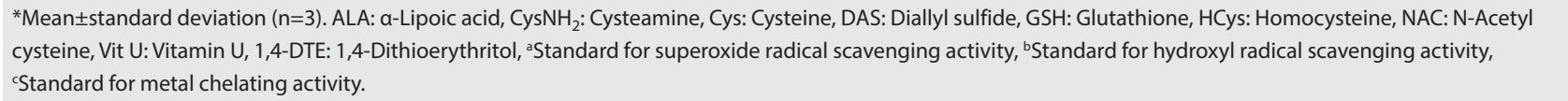 } \\
\hline
\end{tabular}


present in E. spectabilis M. Bieb. varied in quantity. According to our results, it was found that the aqueous extract had the poor, the ethanolic extract had the moderate, and the ethyl acetate extract had the more quantity of alkaloids, flavonoids, protein, and tannins, respectively. On the other hand, anthraquinones and diterpenes were found to be of a higher degree in the ethanolic extract, while the aqueous extract was only rich in phenolics. All other phytochemical constituents in three extracts were detected in low or moderate quantities. The present findings are in line with the results on phytochemical screening wild plants previously published $(13,32)$.

In general, phenolics and flavonoids, ubiquitous in plants such as E. spectabilis M. Bieb., may play crucial roles owing to their antioxidant potentials as well as having beneficial health effects in the prevention of several diseases such as diabetes, cancer, gastrointestinal illnesses, and aging-related disorders $(33,34)$. In the current study, TPCs were found to be at their highest level in ethanolic extract, whereas TFCs were at their lowest level in aqueous extract of $E$. spectabilis M. Bieb. The present findings were inconsistent with those of Ozsoy et al., who reported that the aqueous extracts of Smilax excelsa L. and Amaranthus lividus L. had the highest TPC levels $(35,36)$. On the other hand, it was revealed by Peksel et al., that TPC levels of the alcoholic extract of Pistacia atlantica Desf. leaves were higher than those of ethyl acetate extracts (37). A study by Falahi et al., reported that $E$. spectabilis M.Bieb. extract had the highest TPC levels $(591.00 \pm 111.73 \mathrm{mg} \mathrm{GA}$ equivalent) and TFC levels (18.32 $\pm 2.30 \mathrm{mg} \mathrm{GA}$ equivalent) of the other five traditional Iranian wild edible plants (12). In the study conducted on E. himalaicus, it was reported that the aqueous extract contained more TPCs and TFCs than ethanolic extract (8). The discrepancies between the aforementioned reports and the current study regarding TPCs and TFCs of these extracts may be due to the different geographical origins of the plants as well as the tested part of the herbs.

The reducing power and CUPRAC tests provide a convenient, fast, and simple estimation of total phenolics in plant extracts, as well as the overall antioxidant capacity of plant tissue extracts (21). The FRAP test is also a simple, fast, cost-effective and widely used method that directly assesses the antioxidant potentials of the samples (38). According to our findings, the reducing power and CUPRAC values of both ethanolic and eth$y l$ acetate extracts were higher than those of the aqueous extract. This is in line with the TPCs and TFCs of the same extracts. On the other hand, an increase in FRAP values of all extracts in terms of dose was consistent with TPCs of all extracts in this study. This is similar to the findings of Bernaert et al., (39). Of the sulfur compounds, ALA had a much better FRAP value than the standard compound. A possible explanation for this may be associated with the redox potential of ALA being lower than the ferric-ferrous couple (40). Other sulfur compounds showed weaker ferrous ion reducing capacity. This may be due to the low $\mathrm{pH}$ (pH 3.6) compared to the physiological $\mathrm{pH}$. This low $\mathrm{pH}$ in the FRAP protocol may result in reducing capacity being suppressed depending on protonation on antioxidant compounds, hence providing lower antioxidant activity (41).
Free radical scavenging assays (ABTS, DPPH, and DMPD) are accepted as standard methods (which are simple, rapid, convenient, and fast techniques) based on decolorization reaction for estimation of antioxidant capacities of foods, beverages, pharmaceuticals as well as biological fluids (38). In the present study, it was seen that there was compliance between the TPCs and TFCs of these plant extracts and their free radical scavenging activities. These observations were in line with the previously published outcomes of Mushtaq et al., (8) However, studies on some Indian medicinal plants have also been reported a strong correlation between TPCs and antiradical activity (42). In addition, Gaggeri et al., reported that ethanolic root extracts of two Eremurus species had very close antiradical activities (43). As for comparisons of sulfur compounds and standard antioxidants, Cys $\mathrm{NH}_{2}$ exhibited a better DPPH radical scavenging activity and GSH, NAC, and 1,4-DTE showed the same DMPD radical scavenging activities compared to their respective standards. NAC has also been reported to have better antiradical activity than the standard (44).

The superoxide anion is the main precursor molecule that underpins the formation of $\mathrm{H}_{2} \mathrm{O}_{2}$, and the hydroxyl radical, which triggers oxidative damage in lipids, proteins, and DNA (11). Metal ions in the organism such as free Fe(II) ion can provide an unwanted increase in the production of ROS via distinct reactions viz., Fenton reactions (45). Any substance having the ability to chelate iron can be valuable in terms of antioxidant properties by delaying metal-catalyzed oxidation of ROS (46). In a study on the radical mopping effects of Asphodelus aestivus Brot. extracts conducted by Peksel and her colleagues, $1 \mathrm{mg} / \mathrm{mL}$ of methanolic extract exhibited a strong scavenging effect on superoxide radicals (47). These findings were found to be lower than the outcomes of the current study. Similar results were reported by Eddine et al., (48). In the current study, all extracts exhibited more effective hydroxyl radical scavenging activities than GA. These observations were higher than previously published article by Sacan et al., who reported that the extract of Eruca sativa Mill. also had hydroxyl radical scavenging activity (49). On the other hand, both ALA and DAS exhibited the best hydroxyl radical scavenging activities among all the tested samples (extracts, sulfur compounds, and standards). When the extracts were compared in terms of metal chelating activities, it was found that all extracts showed strong metal chelating activities when compared to GA, but they exhibited weak metal chelating activities in comparison with EDTA. This may be attributed to its richness in varied amounts of bioactive constituents, which reportedly include resveratrol and flavonoids (e.g., rutin, morin, and quercetin) (50). In addition, due to their hydroxyl groups or carbonyl moieties in structure, these flavonoids may contribute to the higher chelating ability of the extracts (51). In contrast, among the sulfur compounds, only $\mathrm{CysNH}_{2}$ was observed to have almost the same metal chelating activity as EDTA. The reason that $\mathrm{CysNH}_{2}$ has the highest metal chelating activity among other sulfur compounds may be due to the free thiol group in its structure. 


\section{CONCLUSIONS}

In the current study, the antioxidant activities of different extracts of E. spectabilis M. Bieb. and important sulfur compounds were investigated. Taken together, the present findings revealed that all extracts of E. spectabilis M. Bieb. exerted considerable antioxidant potential against different radicals in vitro. Moreover, it was observed that the ethyl acetate extract had a better radical scavenging effect than the other extracts. On the other hand, DAS was found to have the highest antioxidant activity out of the studied sulfur compounds. From this point of view, it may be considered that E. spectabilis M. Bieb. may be a good source of potent antioxidants in the prevention of oxidative stress-mediated disorders. In addition, more research should be done to determine the possible beneficial effects of these sulfur compounds on health.

Acknowledgement: This study was supported by Istanbul University-Cerrahpaşa Scientific Research Projects Units with the grant numbers 22605 and UDP-55170.

Informed Consent: Written consent was obtained from the participants.

Peer Review: Externally peer-reviewed.

Author Contributions: Conception/Design of Study- B.B.B., R.Y.; Data Acquisition- B.B.B.; Data Analysis/InterpretationB.B.B., R.Y.; Drafting Manuscript- B.B.B., R.Y.; Critical Revision of Manuscript- B.B.B., R.Y.; Final Approval and AccountabilityB.B.B., R.Y.

Conflict of Interest: Authors declared no conflict of interest.

Financial Disclosure: Authors declared no financial support.

\section{REFERENCES}

1. Hayta S, Polat R, Selvi S. Traditional uses of medicinal plants in Elazığ (Turkey). J Ethnopharmacol 2014; 154(3): 613-23.

2. Güler B, Erkan Y, Uğurlu E. Traditional uses and ecological resemblance of medicinal plants in two districts of the Western Aegean Region (Turkey). Environ Dev Sustain 2020; 22(3): 2099-120.

3. Beiranvand M, Beiranvand F. Iranian plant Eremurus persicus: An overview of botany, traditional uses, phytochemistry and pharmacology. Nat Prod Res 2021; doi: 10.1080/14786419.2021.1916744 [Epub ahead of print].

4. Mehdiyeva N, Fayvush G, Aleksanyan A, Alizade V, Paniagua Zambrana NY, Bussmann RW. Eremurus spectabilis M. Bieb. Xanthorrhoeaceae. Bussmann RW, editor. Ethnobotany of the Caucasus. Cham: Springer International Publishing; 2017.p. 285-88.

5. Baytop T. Türkiye'de Bitkiler ile Tedavi: Geçmişte ve Bugün. Ankara: Nobel Tıp Kitabevleri 1999.s.185.

6. Karaoğlan ES, Albayrak A, Kutlu Z, Bayır Y. Gastroprotective and antioxidant effects of Eremurus spectabilis Bieb. methanol extract and its isolated component isoorientin on indomethacin induced gastric ulcers in rats. Acta Cir Bras 2018; 33: 609-18.

7. Abubaker SR, Hidayat HJ. Anti-tumor potential of local aslerk ( $E r$ emurus spectabilis) leaf extracts by HPLC and applying on cancer cell lines in vitro. Iraqi J Cancer Med Genet 2015; 8(2): 123-8.
8. Mushtaq A, Masoodi MH, Wali AF, Ganai BA. Total phenolic content, total flavonoid content, in vitro antioxidant activity and antimicrobial activity against human pathogenic bacteria of Eremurus himalaicus-An edible herb of North Western Himalayas. Free Radic Antioxid 2017; 7(1): 90-4.

9. Bayrak BB, Yanardag R. Histone deacetylase, xanthine oxidase and urease inhibitory activities of Eremurus spectabilis M. Bieb. extracts. Experimed 2021a; 11(2): doi: 10.26650/experimed.2021.913680 [Epub ahead of print].

10. Bayrak BB, Yanardag R. Inhibitory effects of aqueous extract of Eremurus spectabilis $\mathrm{M}$. Bieb. on diabetes mellitus and skin related enzymes. Istanbul J Pharm 2021b; 51(2): doi: 10.26650/IstanbulJPharm.2021.934461 [Epub ahead of print].

11. Njoya E. Medicinal plants, antioxidant potential, and cancer. Preedy VR, Pattel VB, editors. $2^{\text {nd }}$ ed., Cancer: Oxidative Stress and Dietary Antioxidants. London: Academic Press; 2021.p. 349-57.

12. Falahi E, Delshadian Z, Ahmadvand H, Jokar S. Head space volatile constituents and antioxidant properties of five traditional Iranian wild edible plants grown in west of Iran. AIMS Agric Food 2019; 4(4): 1034-53.

13. Adawia K, Rawaa AK, Ghalia S. Phytochemical screening and antioxidant activity of selected wild plants in Liliaceae family growing Syria. Int J Pharmacogn Phytochem Res 2016; 8(12): 2025-32.

14. Zhu H, Dronamraju V, Xie W, More SS. Sulfur-containing therapeutics in the treatment of Alzheimer's disease. Med Chem Res 2021; 30: 305-52.

15. Komarnisky LA, Christopherson RJ, Basu TK. Sulfur: Its clinical and toxicologic aspects. Nutrition 2003; 19(1): 54-61.

16. Francioso A, Baseggio Conrado A, Mosca L, Fontana M. Chemistry and biochemistry of sulfur natural compounds: Key intermediates of metabolism and redox biology. Oxid Med Cell Longev 2020; 2020: 8294158.

17. Aiyelaagbe OO, Osamudiamen PM. Phytochemical screening for active compounds in Magnifera indica leaves from Ibadan, Oyo State. Plant Sci Res 2009; 2(1): 11-3.

18. Slinkard K, Singleton VL. Total phenols analysis: Automation and comparison with manual methods. Am J Enol Vitic 1997; 28(1): 4955.

19. Zhishen J, Mengcheng T, Jianming W. The determination of flavonoid contents in mulberry and their scavenging effects on superoxide radicals. Food Chem 1999; 64(4): 555-9.

20. Oyaizu M. Studies on products of browning reaction: Antioxidative activities of browning reaction prepared from glucose amine. Jpn J Nutr Diet 1986; 44(6): 307-15.

21. Apak R, Güçlü K, Özyürek M Karademir SE. Novel antioxidant capacity index for dietary polyphenols and vitamin $C$ and $E$, using their cupric ion reducing capability in the presence of neocuproine: CUPRAC method. J Agric Food Chem 2004; 52(26): 7970-81.

22. Benzie IFF, Strain JJ. The ferric reducing ability of plasma (FRAP) as a measure of antioxidant power": The FRAP assay. Anal Biochem 1996; 239(1): 70-6.

23. Arnao MB, Cano A, Acosta M. The hydrophilic and lipophilic contribution to total antioxidant activity. Food Chem 2001; 73(2): 23944.

24. Brand-Williams W, Cuvelier ME, Berset C. Use of a free radical method to evaluate antioxidant activity. LWT-Food Sci Technol 1995; 28(1): 25-30.

25. Fogliano V, Verde V, Randazzo G, Ritieni A. Method for measuring antioxidant activity and its application to monitoring the antioxidant capacity of wines. J Agric Food Chem 1999; 47(3): 1035-40.

26. Liu F, Ooi VEC, Chang ST. Free radical scavenging activities of mushroom polysaccharide extracts. Life Sci 1997; 60(10): 763-71. 
27. Sakanaka S, Tachibana Y, Okada Y. Preparation and antioxidant properties of Japanese persimnon leaf tea (kakinoha-cha). Food Chem 2005; 89(4): 569-75.

28. Decker EA, Welch B. Role of ferritin as a lipid oxidation catalyst in muscle food. J Agric Food Chem. 1990; 38(3): 674-7.

29. Alqethami A, Aldhebiani AY. Medicinal plants used in Jeddah, Saudi Arabia: Phytochemical screening. Saudi J Biol Sci 2021; 28(1): 805-12.

30. Bandiola TMB. Extraction and qualitative phytochemical screening of medicinal plants: A brief summary. Int J Pharm 2018; 8(1): 13743.

31. Velu G, Palanichamy V, Rajan AP. Phytochemical and pharmacological importance of plant secondary metabolites in modern medicine. Roopan S, Madhumitha G, editors. Bioorganic Phase in Natural Food: An Overview. Cham: Springer; 2018.p.135-56.

32. Benzidia B, Barbouchi M, Hammouch H, Belahbib N, et al. Chemical composition and antioxidant activity of tannins extract from green rind of Aloe vera (L.) Burm. F. J King Saud Univ Sci 2019; 31(4): 117581.

33. Salehi B, Ayatollahi SA, Segura-Carretero A, Kobarfard F, Contreras MDM, Faizi $M$, et al. Bioactive chemical compounds in Eremurus persicus (Joub. \& Spach) Boiss. essential oil and their health implications. Cell Mol Biol 2017; 63(9): 1-7.

34. Dhalaria R, Verma R, Kumar D, Puri S, Tapwal A, Kumar V, et al. Bioactive compounds of edible fruits with their anti-aging properties: A comprehensive review to prolong human life. Antioxidants, 2020; 9(11): 1123.

35. Ozsoy N, Can A, Yanardag R, Akev N. Antioxidant activity of Smilax excelsa L. leaf extracts. Food Chem 2008; 110(3): 571-83.

36. Ozsoy N, Yilmaz T, Kurt O, Can A, Yanardag R. In vitro antioxidant activity of Amaranthus lividus L. Food Chem 2009; 116(4): 867-72.

37. Peksel A, Arisan-Atac I, Yanardag R. Evaluation of antioxidant and antiacetylcholinesterase activities of the extracts of Pistacia atlantica Desf. Leaves. J Food Biochem 2010; 34(3): 451-76.

38. Munteanu IG, Apetrei C. Analytical methods used in determining antioxidant activity: A review. Int J Mol Sci 2021; 22(7): 3380.

39. Bernaert N, De Paepe D, Bouten C, De Clercq H, Stewart D, Van Bockstaele $\mathrm{E}$ et al. Antioxidant capacity, total phenolic and ascorbate content as a function of the genetic diversity of leek (Allium ampeloprasum var. porrum). Food Chem 2012; 134(2): 669-77.
40. Moini H, Packer L, Saris NEL. Antioxidant and prooxidant activities of a-lipoic acid and dihydrolipoic acid. Toxicol Appl Pharmacol 2002; 182(1): 84-90.

41. Güngör N, Özyürek M, Güçlü K, Demirci Çekiç S, Apak R. Comparative evaluation of antioxidant capacities of thiol-based antioxidants measured by different in vitro methods. Talanta 2011; 83(5): 1650-8.

42. Surveswaran S, Cai YZ, Corke H, Sun M. Systematic evaluation of natural phenolic antioxidants from 133 Indian medicinal plants. Food Chem 2007; 102(3): 938-53.

43. Gaggeri R, Rossi D, Mahmood K, Gozzini D, Mannucci B, Corana F, et al. Towards elucidating Eremurus root remedy: Chemical profiling and preliminary biological investigations of Eremurus persicus and Eremurus spectabilis root ethanolic extracts. J Med Plant Res 2015; 9(41): 1038-48.

44. Ates $B, A$ braham $L$, Ercal N. Antioxidant and free radical scavenging properties of $\mathrm{N}$-acetylcysteine amide (NACA) and comparison with $\mathrm{N}$-acetylcysteine (NAC). Free Radic Res 2008; 42(4): 372-7.

45. Sánchez, M, Sabio L, Gálvez N, Capdevila M, Dominguez-Vera JM. Iron chemistry at the service of life. IUBMB Life 2017; 69(6): 382-8.

46. Sabraoui T, Khider T, Nasser B, Eddoha R, Moujahid A, Benbachir M. et al. Determination of punicalagins content, metal chelating, and antioxidant properties of edible pomegranate (Punica granatum L) peels and seeds grown in Morocco. Int J Food Sci 2020; 2020: 8885889 .

47. Peksel A, Imamoglu S, Altas Kiymaz N, Orhan N. Antioxidant and radical scavenging activities of Asphodelus aestivus Brot. extracts. Int J Food Prop 2013; 16(6): 1339-50.

48. Eddine LS, Segni L, Redha OM, Noureddine G. Free radical scavenging activity of leaf extract of Rumex vesicarius $L$. obtained by different methods. Int J Toxicol Pharmacol Res 2015; 7(3): 140-6.

49. Sacan O, Orak H, Yanardag R. Antioxidant activity of water extract of Eruca sativa Mill. Asian J Chem 2008; 20(5): 3462-74.

50. Bircan B, Kırbağ S. Determination of antioxidant and antimicrobial properties of Eremurus spectabilis Bieb. ACU J For Fac 2015; 16(2): 176-186.

51. Kejík Z, Kaplánek R, Masařík M, Babula P, Matkowski A, Filipenský $\mathrm{P}$, et al. Iron complexes of flavonoids-antioxidant capacity and beyond. Int J Mol Sci 2021; 22(2): 646. 